www.jmscr.igmpublication.org

Impact Factor (SJIF): 6.379

Index Copernicus Value: 71.58

ISSN (e)-2347-176x ISSN (p) 2455-0450

crossrefDOI: https://dx.doi.org/10.18535/jmscr/v6i7.177

Journal Of Medical Science And Clinical Research

IGM Publication

An Official Publication of IGM Publication

\title{
RNFL defect with vitamin B12 deficiency correlating diet pattern: Experience in tertiary care hospital
}

\section{Swati Samant ${ }^{1}$, Srikant Kumar Dhar ${ }^{2 *}$, Priyanka Samal $^{3}$, Suchismita Mishra ${ }^{1}$ Ankita Choudhury ${ }^{4}$, Nikita Jaiswal ${ }^{4}$, Mahesh Chandra Sahu ${ }^{5}$}

${ }^{1}$ Assistant Professor, Department of Ophthalmology, IMS and SUM hospital, Siksha "O" Anusandhan Deemed to be University, K8, Kalinganagar, Bhubaneswar-751003, Odisha, India

${ }^{2}$ Associte Professor, Department of Medicine, IMS and SUM hospital, Siksha “O” Anusandhan Deemed to be University, K8, Kalinganagar, Bhubaneswar-751003, Odisha, India

${ }^{3}$ Associte Professor, Department of Hematology, IMS and SUM hospital, Siksha "O" Anusandhan Deemed to be University, K8, Kalinganagar, Bhubaneswar-751003, Odisha, India

${ }^{4} J u n i o r$ Resident, Department of Ophthalmology, IMS and SUM hospital, Siksha "O" Anusandhan Deemed to be University, K8, Kalinganagar, Bhubaneswar-751003, Odisha, India

${ }^{5}$ Assistant Professor, Directorate of Medical Research, IMS and SUM hospital, Siksha "O" Anusandhan Deemed to be University, K8, Kalinganagar,Bhubaneswar-751003, Odisha, India

*Corresponding Author

Dr Srikant Kumar Dhar

Associate Professor, Dept of Medicine, IMS and SUM hospital, Siksha "O" Anusandhan Deemed to be University Email:drskdhar@gmail.com

\begin{abstract}
Purpose: Comparision of peri-papillary nerve fibre layer (RNLF) thickness of patients with vitamin B12 deficiency with that of healthy controls measured by $3 D$ spectral domain Optical Coherence Tomography $(O C T)$ and to evaluate the correlation between peri-papillary RNFL thickness and plasma vitamin B12 levels and their association with vegetarian diet pattern.

Material and Methods: 25 patients with a diagnosis of vitamin B12 deficiency and 25 age and sex matched controls were included in this prospective study. Blood count, vitamin B12 level, folate level, and other biochemical parameters were obtained for all the cases and controls. Temporal, nasal, inferior and superior peripapillary RNFL thickness were obtained using 3D spectral domain OCT. Disc area, rim area and cube volume were also measured.

Result: Mean age of the patient and control group was $34.40 \pm 10.90$ and $34.36 \pm 9.38$ respectively. Mean plasma vitamin B12 level was $160.84 \pm 40.65$ in the group and $471.32 \pm 86.88$ in the control group. $(p<$ 0.001). There was no significant difference between the two groups concerning disc area (DA), rim area $(R A)$, cup volume $(C V)$ and RNFL thickness in superior, inferior and nasal quadrants. However RNFL in temporal quadrant was significantly thinner in the patient group than in the control group $(p<0.001)$. Temporal RNFL thickness had a strong correlation with vitamin B12 levels.). (0.004). It was further noted that the vitamin B12 deficiency was significantly related to the vegetarian population.

Conclusion: Our study showed that temporal quadrant RNFL thickness was thinner in patients with vitamin B12 deficiency and it was correlated with the plasma vitamin B12 levels. Moreover it was found more in persons with vegetarian diet pattern.

Keywords: RNFL, OCT, vitamin B12, diet.
\end{abstract}




\section{Introduction}

Vitamin B12 is an essential vitamin required for normal central and peripheral nervous system functions ${ }^{1,2}$. It plays an important role in DNA synthesis, thus maintaining normal neurological function, protein metabolism and erythropoiesis ${ }^{1}$ Eggs, milk, poultry, meat, cheese, fish, shellfish etc. are a very rich source of vitamin $\mathrm{b} 12^{3,4}$. Its deficiency can occur as a result of vegetarian diet, autoimmune or parasitic diseases, drugs, malabsorbption and genetic defects such as transcobalamin 2 polymorphism ${ }^{5}$. It's deficiency is associated with megaloblastic anaemia, gastrointestinal and neuropsychiatric manifestation ${ }^{6}$. The neurological manifestations include myelopathy, peripheral neuropathy, encephalopathy $^{7,8,9}$ These neurological disorders can be seen without haematological abnormalities. Thus diagnosis is difficult in subclinical Vitamin B12 deficiency without anaemia ${ }^{10,11}$. However if treatment is delayed, these patients may have permanent neurological sequelae ${ }^{12}$. In eye, vitamin B12 has been related to optic neuropathy and retinal nerve fibre thinning ${ }^{13}$. Spectral domain optical coherence tomography is a useful method to study this RNFL (Retinal nerve fibre thickness) which can be used in patients with Vitamin B12 deficiency. Measurement of RNFL thickness by OCT has been used for diagnosis of various neurological and neuro-ophthalmic diseases such as multiple sclerosis, Alzheimer's disease and Parkinson's disease ${ }^{14,15,16}$.

\section{Aim and Objective}

The objective of our study was to measure the peripapillary retinal nerve fiber layer (RNFL) thickness measured by using spectral domain OCT in patients with vitamin B12 deficiency and compare it with age and sex matched healthy controls in an Eastern Indian population and to evaluate the correlation between RNFL thickness with plasma vitamin B12 levels and vegetarian diet patterns.

\section{Material and Methods}

25 eyes of 25 patients with vitamin B12 deficiency were compared with 25 eyes of 25 age and sex matched healthy individuals. One eye of each patient was taken randomly for study. Similarly in controls also one eye of each patient was randomly included. The study was carried out in IMS \& SUM hospital, Odisha for over a period of 2 years from January2016 to January 2018. Patients with serum vitamin B12 levels of less than197 pg/ml were considered as vitamin B12 deficient. All the participants underwent neurological evaluation to exclude other causes of neuropathy. Patients with other illness like diabetes mellitus, hypertension, dyslipidemia, thyroid disorders, chronic infections e.g. Tuberculosis, were excluded from study. All the patients were informed in detail about the study procedure and asked for consent to participate in the study.

As per our hospital protocols, each patients sequentially underwent visual acuity Testing (snellens chart), slit lamp examination, tonometry (goldmann applanation method), central corneal thickness, perimetry (humphrey) and fundoscopy. Patients with any corneal abnormalities, retinal diseases, glaucoma, strabismus, disorders of optic nerve and neurological disorders, previous ocular trauma/surgery or history of intake of steroids or antiglaucoma drugs were excluded from the study. OCT measurements were done by a blind investigator using spectral domain HD OCT. The measurements obtained were temporal, nasal, inferior and superior RNFL thickness, disc area (DA), rim area (RA), and cup area(CA).The levels of plasma vitamin b12 were measured using Chemiluminescence Cobas E 411 auto analyser. The normal ranges of vitamin B12 were 197-816 $\mathrm{pg} / \mathrm{ml}$ according to manufacturer's instructions.

\section{Statistical Analysis}

Statistical analysis was performed using SPSS version 20. Statistical significance was set up at $<0.05$. Paired t-test was used to compare between the patient and control groups. Correlation coefficient to calculate the relationship between 
the RNFL thickness and the level of vitamin B12

was done using Chi square test.

\section{Results}

Table 1: Clinical characteristics of the group

\begin{tabular}{|c|c|c|c|c|c|}
\hline Characteristics & $\begin{array}{c}\text { Patient } \\
\text { group (mean) }\end{array}$ & $\begin{array}{c}\text { Control } \\
\text { group(mean) }\end{array}$ & $\begin{array}{c}\text { Standard deviation } \\
\text { of patients }\end{array}$ & $\begin{array}{l}\text { Standard deviation of } \\
\text { controls }\end{array}$ & $\mathrm{P}$ value \\
\hline Age ( years) & 34.40 & 34.36 & 10.90 & 9.38 & 0.98 \\
\hline $\operatorname{Sex}(\mathrm{M} / \mathrm{F})$ & $12 / 13$ & $13 / 12$ & --- & --- & --- \\
\hline $\begin{array}{l}\text { Vit B12 } \\
(\mathrm{pg} / \mathrm{ml})\end{array}$ & 160.84 & 471.32 & 40.65 & 86.88 & 0.0001 \\
\hline $\mathrm{CV}\left(\mathrm{mm}^{2}\right)$ & 0.22 & 0.23 & 0.33 & 0.32 & 0.96 \\
\hline $\mathrm{RA}\left(\mathrm{mm}^{2}\right)$ & 1.28 & 1.268 & 0.15 & 0.11 & 0.75 \\
\hline $\mathrm{DA}\left(\mathrm{mm}^{2}\right)$ & 2.060 & 2.064 & 0.02 & 0.02 & 0.25 \\
\hline \multicolumn{6}{|l|}{$\begin{array}{l}\text { Peripapillary } \\
\text { RNFL thickness }\end{array}$} \\
\hline $\begin{array}{l}\text { Temporal } \\
\text { quadrant }\end{array}$ & 50.60 & 67.28 & 11.74 & 9.00 & 0.0001 \\
\hline Superior quadrant & 111.44 & 112.24 & 11.76 & 12.40 & 0816. \\
\hline $\begin{array}{l}\text { Nasal } \\
\text { Quadrant }\end{array}$ & 74.96 & 77.08 & 8.69 & 8.22 & 0.370 \\
\hline Inferior quadrant & 112.28 & 116.20 & 8.38 & 6.99 & 0.070 \\
\hline \multicolumn{6}{|l|}{ Food habits } \\
\hline Non vegetarian & 6 & 16 & ------ & ----- & \\
\hline Vegetarian & 19 & 9 & ---- & ------ & 0.004 \\
\hline
\end{tabular}

Table 2 : Correlation between RNFL thickness and plasma vitamin B12 levels in the study subjects.

\begin{tabular}{|l|c|}
\hline RNFL thickness & Correlation coefficient \\
\hline Temporal & 0.28 \\
\hline Superior & 0.149 \\
\hline Nasal & 0.231 \\
\hline Inferior & 0.335 \\
\hline
\end{tabular}

superior RNFL in pt.

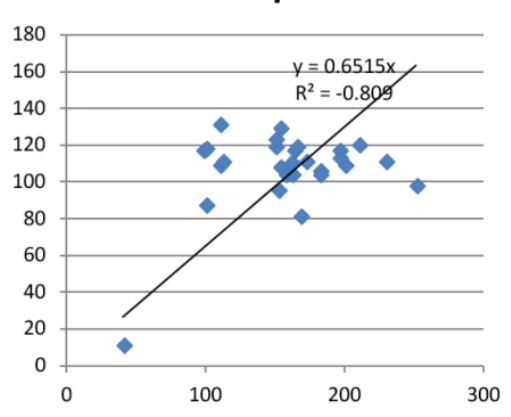

- superior RNFL in pt.

— Linear (superior RNFL in pt.)

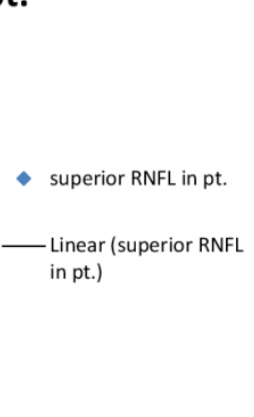

Inferior RNFL in pt.

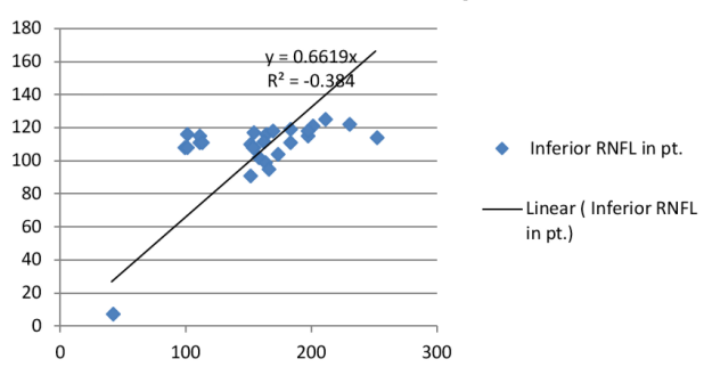

Nasal RNFL in pts.

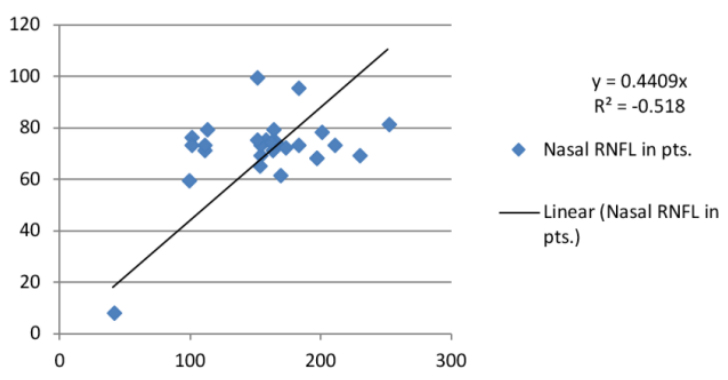

Temporal RNFL in pt.

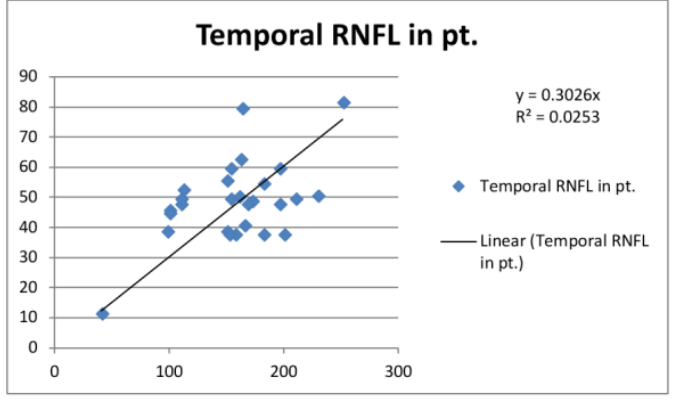


The mean age group of the patient and control group was 34.00 and 34.36 respectively. Out of 25 patients, 7 patients had peripheral neuropathy and the rest 18 patients were asymptomatic. All the subjects in patient and control group had a visual aquity of 6/6. Humphrey perimetry in all the patients were within normal limits. The CCT corrected IOP and axial length were also within normal range in both the groups. The patient and control group were similar regarding plasma folate levels. Mean plasma vitamin b12 level was 160.84 in the patient group and 471.32 in the control group. There was no significant difference between the two groups concerning DA (disc area), RA (rim area), CA (cup area), RNFL thickness inferior and nasal quadrants. However RNFL in the temporal quadrant was significantly thinner in the patient group than the control group $(\mathrm{p}<0.0001)$. Further the vitamin b12 deficiency was significantly related to the vegetarian population (0.004). The second table shows the correlation coefficient between the RNFL thickness in various quadrants and vitamin B12 levels in patient groups. Temporal RNFL thickness had a strong correlation with the plasma vitamin B12 levels (correlation coefficient $=0.0253$ ). But superior, inferior and nasal RNFL thickness had no correlation with vitaminB12 levels.

\section{Discussion}

Our study revealed that temporal RNFL was thinner in patients with vitamin B12 deficiency than in healthy controls as measured by OCT. In addition, the temporal RNFL thickness was directly related to vitamin B12 levels. Further this vitamin B12 deficiency was significantly more in vegetarian population.

Vitamin B12 contributes the production of myelin nerve sheath in our nervous system. The neurological and psychiatric manifestations related to its deficiency are caused by deterioration of myelin ${ }^{24}$. Other than hematological disorders, vitamin B12 deficiency has been associated with various neuropsychiatric and neuro-ophthalmologic diseases such as cognitive dysfunctions, dementia, ataxia, peripheral neuropathy, myelopathy, optic neuropathy, bilateral abducens palsy, upward gaze palsy, total ophthalmoplegia, internuclear ophthalmoplegia, and nystagmus ${ }^{17,25}$. According to a study neurological involvement causes demyelination, that leads to axonal degeneration and finally irreversible cell damage due to axonal death $^{18}$..Another study demonstrated that vitamin B12 deficiency reduced nerve fibers in the nerve fiber layer of the retina ${ }^{19}$.

The measurement of RNFL thickness by OCT has become a important diagnostic tool to diagnose neurological and neuro-ophthalmic diseases in recent years. Conditions like optic neuropathies, optic neuritis, multiple sclerosis, Alzheimer's disease, and Parkinson's disease have had shown to have peripapillary thinning ${ }^{20}$. Peripapillary RNFL thinning has been found to occur in temporal quadrant in optic neuropathies such as optic neuritis and ethambutol optic neuropathy . Özkasap et al. concluded that the mean RNFL was thinner in children with vitamin B12 deficiency ${ }^{26}$. Türkyılmaz et al. stated that the mean RNFL and temporal RNFL were thinner in adults with deficiency of B12 vitamins ${ }^{27}$. Likewise, vitamin B12 deficiency caused RNFL thinning in temporal quadrant in adult population as in our study .RNFL has been found to be thinner in superior and inferior quadrants in patients with Alzheimer's disease $^{21}$. RNFLs of inferior and temporal quadrants were thinner in patients with Parkinson's disease as per a retrospective study ${ }^{22}$. RNFL in glaucoma is affected before the occurrence of irreversible progression of optic disc excavation and visual field defects ${ }^{23}$. Perimetrically normal hemifields of glaucomatous eyes had significantly thinner peripapillary RNFLs as compared to RNFL of healthy eyes as described by Na.at al. Similarly, none of our patients with vitamin B12 deficiency had visual impairment or visual field defect. Thus, it can be said that temporal peripapillary RNFL thinning in our patients with vitamin B12 deficiency might be a sign of structural subclinical damage. 


\section{Conclusion}

In our study, we came to the conclusion that similar to other optic neuropathies, the temporal retinal nerve fibre thinning was seen in patients with vitamin B12 deficiency as compared to controls (in our study population). Further we found that this deficiency and consequently the RNFL thinning were directly related to predominance of vegetarian diet in the patient. We believe that further studies on a larger scale is required for confirmation of these findings.

Studies are also warranted to assess the effect of vitamin B12 replacement therapy on the peripapillary retinal nerve fiber layer (RNFL) thickness.

Conflict of interest: The authors have no conflicts of interest to be declared.

\section{Source of Funding: Self}

Ethical committee clearance was taken from institutional ethical committee

\section{References}

1. Pineles SL, Avery RA, Liu GT . Vitamin B12 optic neuropathy in autism. Pediatrics 2010 ; 126 : e967 - e970.

2. Perez L, Heim L, Sherzai A, Jaceldo-Siegl K, Sherzai A. Nutrition and vascular dementia. J Nutr Health Aging, 2012 ; 16 : 319 .

3. Schrier SL. Physiology of vitamin B12 and folate deficiency. In: UpToDate, Motil, KJ (Ed), UpToDate, Waltham, MA. 1, 2016.

4. 324 Food sources of vitamin B12 [Internet]. Dietitians of Canada; 29, 2016.

5. Scalabrino G . Cobalamin (vitamin B(12)) in subacute combined degeneration and beyond: traditional interpretationsand novel theories. Exp Neurol 2005 ; 192 : $463-479$

6. Whitehead VM, Rosenblatt DS, Cooper BA (2003) Megaloblastic anemia. In: Nathan DG, Orkin SH, Ginsburg D, Look AT (eds) Nathan and Oski's hematology of infancy and childhood, 6th edn. WB Saunders, Philadelphia, pp 419-455

7. Kumar N. Acute and subacute encephalopathies: deficiency states (nutritional). Semin Neurol 2011 ; $31: 169-183$.

8. de Lau LM, Smith AD, Refsum H, Johnston C, Breteler MM . Plasma vitamin B12 status and cerebral white-matter lesions. J Neurol Neurosurg Psychiatr $2009 ; 80: 149-157$.

9. Dalla Torre C, Lucchetta M, Cacciavillani M , Campagnolo M ,Manara R , Briani C .Reversible isolated sensory axonal neuropathy due to cobalamin defi ciency. Muscle Nerve $2012 ; 45: 428$ - 430 .

10. Carmel R, Sinow RM, Karnaze DS (1987) Atypical cobalamin deficiency. Subtle biochemical evidence of deficiency is commonly demonstrable in patients without megaloblastic anemia and is often associated with protein-bound cobalamin malabsorption. J Lab Clin Med 109:454463

11. Lindenbaum J, Healton EB, Savage DG, Brust JC, Garrett TJ, Podell ER, Marcell PD, Stabler SP, Allen RH (1988) Neuropsychiatric disorders caused by cobalamin deficiency in the absence of anemia or macrocytosis. N Engl J Med 318:1720-1728 .

12. Beck WS (1991) Neuropsychiatric consequences of cobalamin deficiency. Adv Intern Med 36:33-56

13. 13.Pineles SL, Avery RA, Liu GT . Vitamin B12 optic neuropathy in autism. Pediatrics 2010 ; 126 : e967 - e970.

14. 14.Pueyo V, Ara JR, Almarcegui C , Martin J , Güerri N , García E et al. Subclinical atrophy of the retinal nerve fibre layer in multiple sclerosis. Acta Ophthalmol $2010 ; 88: 748-752$.

15. Paquet C, Boissonnot $\mathrm{M}$, Roger $\mathrm{F}$, Dighiero P , Gil R , Hugon J . Abnormal retinal thickness in patients with mild 
cognitive impairment and Alzheimer's disease. Neurosci Lett 2007; 420 : 97 - 99.

16. Akdal G, Yener GG , Ada E , Halmagyi GM . Eye movement disorders in vitamin B12 deficiency: two new cases and a review of the literature. Eur J Neurol 2007 ; $14: 1170$ - 1172 .

17. Akdal G, Yener GG, Ada E, Halmagyi GM . Eye movement disorders in vitamin B12 defi ciency: two new casesand a review of the literature. Eur J Neurol 2007 ; $14: 1170$ - 1172.

18. Miller A, Korem M, Almog R, Galboiz Y. Vitamin B12, demyelination, remyelination and repair in multiple sclerosis. J Neurol Sci 2005; 233 : 93 - 97.

19. Amemiya T . The eye and nutrition . Jpn J Ophthalmol $2000 ; 44: 320$.

20. Pasol J . Neuro-ophthalmic disease and optical coherence tomography: glaucoma look-alikes. Curr Opin Ophthalmol 2011 ; $22: 124-132$

21. Lu Y, Li Z, Zhang X, Ming B , Jia J , Wang $R$ et al. Retinal nerve fi ber layer structure abnormalities in early Alzheimer's disease: evidence in optical coherence tomography. Neurosci Lett 2010 ; $480: 69-72$

22. Moschos MM, Tagaris G, Markopoulos I, Margetis I, Tsapakis S, Kanakis M et al. Morphologic changes and functional retinal impairment in patients with Parkinson disease without visual loss. Eur J Ophthalmol $2011 ; 21: 24-29$.

23. Kremmer S , Zadow $\mathrm{T}$, Steuhl KP , Selbach JM . Scanning laser polarimetry in myopic and hyperopic subjects. Graefes Arch Clin Exp Ophthalmol 2004 ; 242 : $489-494$.

24. Black MM. Effects of vitamin B12 and folate deficiency on brain development in children. Food Nutr Bull. 2008;29(2 Suppl):S126-31.
25. Larner AJ. Visual failure caused by vitamin B12 deficiency optic neuropathy. Int J Clin Pract. 2004;58(10):977-78.

26. Ozkasap S, Turkyilmaz K, Dereci S, Oner $\mathrm{V}$, Calapoglu T, Cure MC, et al. Assessment of peripapillary retinal nervefiber layer thickness in children withvitamin B12 deficiency. Childs Nerv Syst. 2013;29(12):2281-86.

27. Turkyilmaz K, Oner V, Turkyilmaz AK, Kirbas A, Kirbas S, Sekeryapan B. Evaluation of peripapillary retinal nerve fiber layer thickness in patients with vitamin B12 deficiency using spectral domain optical coherence tomography. Curr Eye Res. 2013;38(6):680-84. 